\title{
Development of an anti-flood board to protect the interiors and exteriors of the infrastructure
}

\author{
Michal Petru ${ }^{1 \mathrm{a}}$, Pavel Srb ${ }^{1}$, Ladislav Sevcik ${ }^{1}$, Tomas Martinec ${ }^{1}$, and Petr Kulhavy ${ }^{1}$ \\ ${ }^{1}$ Institute for Nanomaterials, Advanced Technologies and Innovation, Technical University of Liberec, Studentská 2 , \\ 461 17, Liberec 1, Czech Republic
}

\begin{abstract}
This article deals with the development of an anti-flood board to protect the interior and exterior of various infrastructures, such a houses, cottages or industrial buildings. It was designed prototypes and assembled numerical simulations. In Central Europe and in particular in the Czech Republic, floods are an integral part of the natural water cycle and cause great loss of life and great property damage. The development of new types of mobile anti-flood boards is very important as the design solution is developed for flood protection with regard to minimizing weight, cost of production, easy manipulation, simplicity and speed of installation.
\end{abstract}

\section{Introduction}

Floods are a natural part of the water cycle. The Czech Republic was hit by devastating floods in past years. These floods have triggered an effort in the development of flood protection measures. For larger cities, it seems advantageous to use flood barriers with the substructure. Barriers with substructure are usually too expensive for small towns and villages. Mobile barriers are here better because they can be easily placed to the affected area. The whole system can be easily moved to great distance, it is appropriate to shared system with towns in various flood areas, where floods are typically at different times. For protection of personal property in areas with low building density are these mobile barriers expensive. Here are the best solution secure individual buildings against water ingress. Hence began the development of lightweight anti-flood board for installation to building bores such as doors and windows. Flood barriers have to meet a number of tests $[1,2]$, such as the impact of a $\log$, resistance to waves etc.

\section{Experimental measurements of mobile flood barriers}

As part of the development of anti-flood systems without substructure, functional prototypes have been assembled and subjected to tests for interior and exterior installation and also in water testing channel in Jap-Jacina company fig.1. Testing conditions based on the prepared certification methodology for testing flood protection systems have been used. An interior and exterior protection layout was prepared. Various case studies of hydrostatic and hydrodynamic loads were tested for a new design solution. A new design has been prepared with regard to minimize weight, cost of production, and ease of handling, simplicity and speed of installation, as shown in fig. 2 .
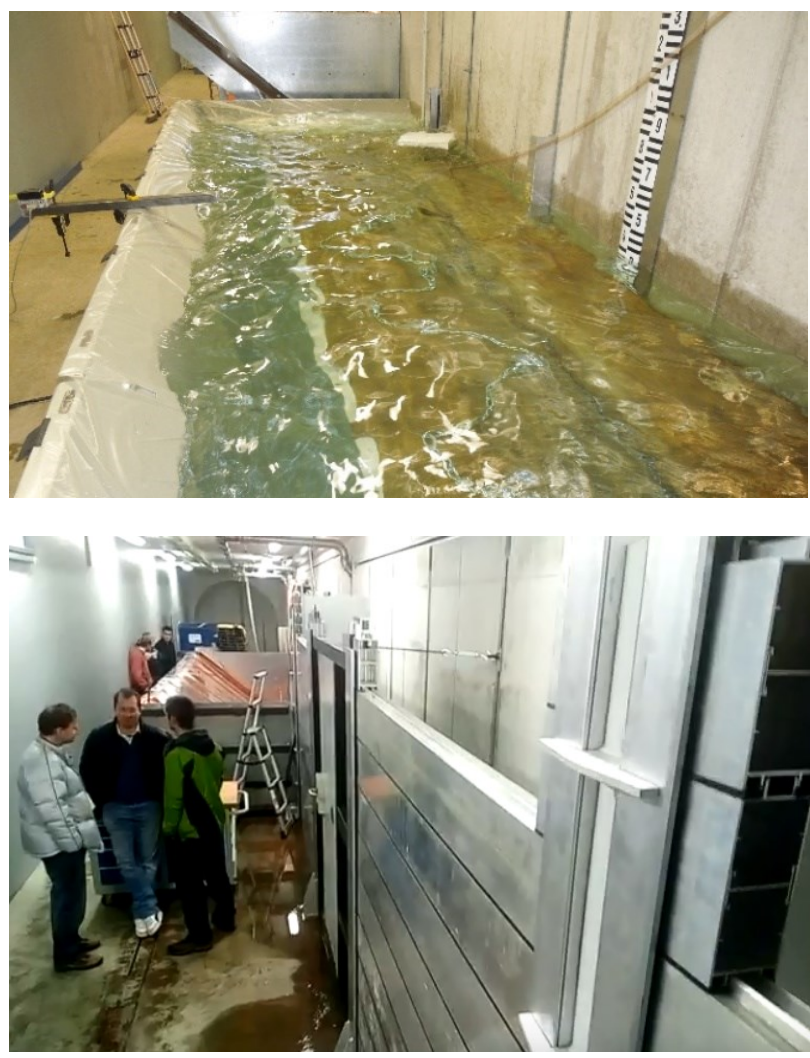

Fig. 1. Experimental testing of hydrostatic and hydrodynamic loads in the water channel (above), preparation of tests for the installation of mobile anti-flood board (below).

\footnotetext{
a Corresponding author: michal.petru@tul.cz
} 


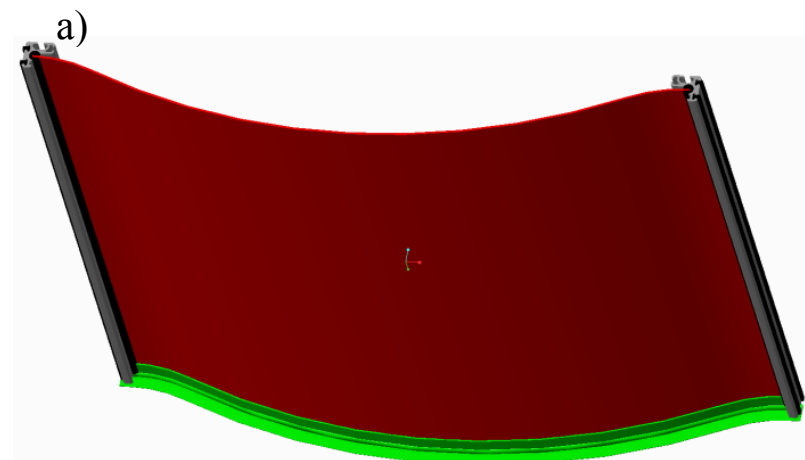

b)

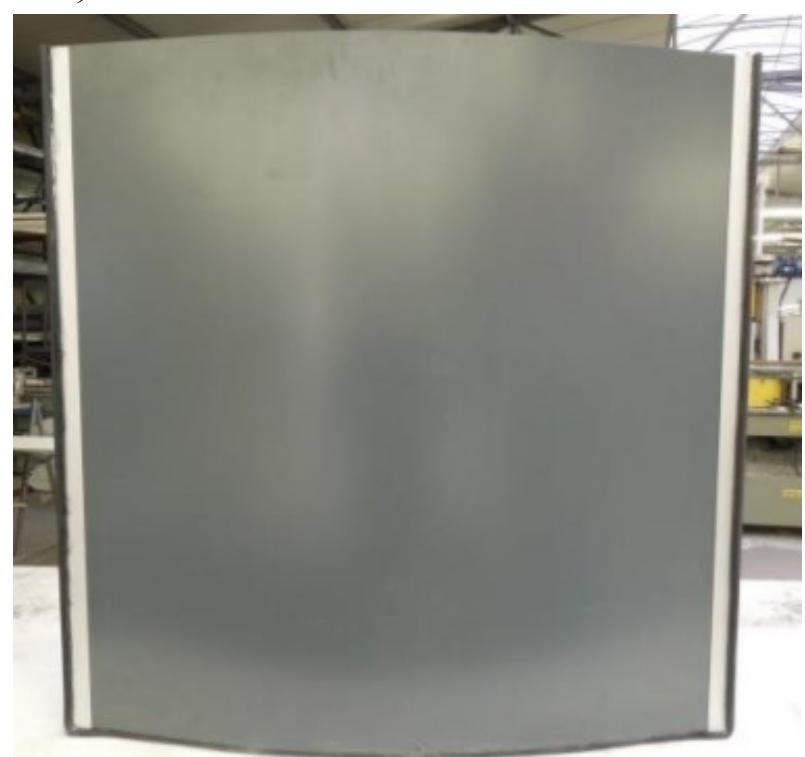

Fig. 2. Development of the prototype of mobile anti-flood board: a) CAD model, b) real prototype

\section{Numerical simulations}

For virtual study of material properties, structural optimization and critical regions of mobile anti-flood board was used coupled Euler and Lagrange technique (CEL), which combine both approaches in one analysis. [manual abaqus] This method was originally developed to simulate of airbag inflation, later to solve problems such as bird - plane collision, aquaplaning, water tank impact load etc. The method consist mesh adjustment, surface reconstruction and solution of liquids and structures equations. The purpose of this technique is to avoid mesh problems in simulations where an extreme deformation occurs. In the simulations is commonly used Lagrangian approach, which is not suitable for cases of excessive deformation. For those cases Eulerian meshing approach is more suitable. The CEL technique captures the strengths of both Lagrange and Euler method. The CEL method allows the user to selectively mesh individual analysis components. Bodies reaching large deformations (liquids, gases, etc.) can be meshed using Eulerian technique, and conventional Lagrange technique can be used for other bodies. Interaction between bodies is determined by the definition of contact. In Lagrange simulations each element represents the volume of material. Movement of material is possible only by mesh deformation. The Lagrange approach is suitable for most structural problems, but in simulations where large deformations are achieved, the elements are distorted and the simulation cannot continue. In Eulerian simulations the mesh remains stationary during the simulation and the material flows through elements that do not deform. The Euler mesh is typically a simple rectangular grid of elements designed to extend well beyond the Eulerian material boundaries, giving the material space to move and deform. For material assignment in Eulerian analysis, it is necessary to use a predefined field of material that uses the principle of material volume fractions. During Eulerian analysis, the presence of material in each element is monitored in terms of material volume fractions. Volume fraction is the percentage of the volume of the element that occupies the material. For elements which are only partially filled with material, the exact geometric composition of the material inside of the element is not known. Abaqus interpolates volume fractions in adjacent elements to estimate material boundaries within an element. Volume fractions are expressed as a number between zero and one, this number means the percentage of filling, e.g. 0.23 means that $23 \%$ of element is filled by assigned material.

\subsection{Material model of water}

Formulation of Equation of state Mie Grüneisen $U_{S}-U_{P}$ form was used as a material model for water in the Abaqus simulation [3]. The most common form of MieGrüneisen is:

$$
p-p_{H}=\Gamma \rho\left(E_{m}-E_{H}\right)
$$

where $\mathrm{p}_{\mathrm{H}}$ and $\mathrm{E}_{\mathrm{H}}$ are the Hugoniot pressure and specific energy (per unit mass) and they are functions of density only. $\Gamma$ is the Grüneisen ratio, which describes the alteration in a crystal lattice's vibration frequency, based on the lattice's increase or decrease in volume as a result of temperature change. It is used in quantum mechanics and it is defined as:

$$
\Gamma=\Gamma_{0} \frac{\rho_{0}}{\rho}
$$

Where $\Gamma_{0}$ is the initial Grüneisen ratio (material constant) and $\rho_{0}$ is the reference density. The Hugoniot energy $E_{H}$ is related to the Hugoniot pressure $p_{H}$ by:

$$
E_{H}=\frac{p_{H} \eta}{2 \rho_{0}}
$$

Where $\eta=1-\rho_{0} / p$ is the nominal volumetric compressive strain. Elimination of $\Gamma$ and $E_{H}$ from the above equations yields:

$$
p=p_{H}\left(1-\frac{\Gamma_{0} \eta}{2}\right)+\Gamma_{0} \rho_{0} E_{m}
$$

The state and the energy equations represent coupled equations for pressure and internal energy. Abaqus solves these equations simultaneously at each material point.

A common form of the Hugoniot data is given by

$$
p_{H}=\frac{\rho_{0} c_{0}^{2} \eta}{(1-s \eta)^{2}}
$$


Where $\mathrm{c}_{0}$ and $\mathrm{s}$ define the linear relationship between the shock velocity $U_{S}$ and the particle velocity $U_{P}$ as follows:

$$
U_{S}=c_{0}+s U_{p}
$$

With the above assumptions the linear $U_{S}-U_{P}$ Hugoniot form is written as

$$
p=\frac{\rho_{0} c_{0}^{2} \eta}{(1-s \eta)^{2}}\left(1-\frac{\Gamma_{0} \eta}{2}\right)+\Gamma_{0} \rho_{0} \mathrm{E}_{\mathrm{m}}
$$

Where

$$
\rho_{0} c_{0}^{2}>0
$$

is equivalent to the elastic bulk modulus at small nominal strains. There is a limiting compression given by the denominator of this form of the equation of state

$$
\begin{gathered}
\eta_{\text {lim }}=\frac{1}{s} \\
\rho_{\text {lim }}=\frac{s \rho_{0}}{s-1}
\end{gathered}
$$

\subsection{Material model of board}

Numerical simulations of mobile anti-flood board have been developed to find the appropriate dimensions, thickness and material to meet cost, production possibilities and assembly requirements. The simulations were designed that the both edges of board were fixed to replace the mounting board in the building bore, and then the hydrostatic pressure was applied to different heights depending on the type of board. A number of simulations have been carried out with different materials and thicknesses for several types of building bores. Composite materials have been selected for their unique properties at low weight compared to steel. Corresponding mechanical properties, depending on weight optimization as well as price, give the glass fiber reinforced composites. For simulations a material model based on the basic equation for describing the mechanical properties of the composite (11) was used. The mechanical properties of this composite structure are influenced by volume of the fibers and the matrix, the thickness of the composite, the number and orientation of layers, etc. [4]. For the optimal price and mechanical properties ratio is the range of fibers volume between $35 \%-50 \%$ (Tab.1.).

$$
\left\{\begin{array}{l}
\varepsilon_{11} \\
\varepsilon_{22} \\
\varepsilon_{33} \\
\gamma_{12} \\
\gamma_{23} \\
\gamma_{13}
\end{array}\right\}=\left[\begin{array}{cccccc}
1 / E_{11} & -v_{12} / E_{11} & -v_{12} / E_{11} & 0 & 0 & 0 \\
-v_{12} / E_{11} & 1 / E_{22} & -v_{23} / E_{22} & 0 & 0 & 0 \\
-v_{12} / E_{11} & -v_{23} / E_{22} & 1 / E_{22} & 0 & 0 & 0 \\
0 & 0 & 0 & 1 / G_{23} & 0 & 0 \\
0 & 0 & 0 & 0 & 1 / G_{12} & 0 \\
0 & 0 & 0 & 0 & 0 & 1 / G_{12}
\end{array}\right] \cdot\left\{\begin{array}{c}
\sigma_{11} \\
\sigma_{22} \\
\sigma_{33} \\
\tau_{12} \\
\tau_{23} \\
\tau_{13}
\end{array}\right\}
$$

Tab. 1. Mechanical properties of composites with epoxy matrix reinforced with glass fibers

\begin{tabular}{|c|c|c|c|c|c|c|}
\hline $\begin{array}{c}V_{f} \\
{[\%]}\end{array}$ & $\begin{array}{c}E_{11} \\
{[\mathrm{GPa}]}\end{array}$ & $\begin{array}{c}E_{22} \\
{[\mathrm{GPa}]}\end{array}$ & $\begin{array}{c}G_{12} \\
{[\mathrm{GPa}]}\end{array}$ & $\begin{array}{c}G_{23} \\
{[\mathrm{GPa}]}\end{array}$ & $\begin{array}{c}v_{12} \\
{[-]}\end{array}$ & $\begin{array}{c}v_{23} \\
{[-]}\end{array}$ \\
\hline 10 & 8,8 & 4,8 & 1,8 & 1,74 & 0,329 & 0,48 \\
\hline 20 & 16,1 & 5,4 & 2,2 & 2,21 & 0,319 & 0,53 \\
\hline 30 & 22,7 & 6,3 & 2,6 & 2,67 & 0,31 & 0,54 \\
\hline
\end{tabular}

\begin{tabular}{|l|c|c|c|c|c|c|}
\hline 40 & 29,2 & 8,4 & 3,1 & 3,23 & 0,289 & 0,52 \\
\hline 50 & 34,3 & 9,9 & 4 & 4,02 & 0,279 & 0,54 \\
\hline
\end{tabular}

\section{Results and discussion}

Figure 3 shows the results of numerical simulations of anti-flood board. Numerical simulation of board for flexural stress analysis at hydrodynamic load was carried out. Lightened glass fibre reinforced composite boards of thickness of $1.5,2$ and $3 \mathrm{~mm}$, was tested. Simulated boards were designed for building bores from $400 \mathrm{~mm}$ to $1000 \mathrm{~mm}$ wide. The simulation of hydrostatic pressure show that a $1.5 \mathrm{~mm}$ thick board is significantly deformed compared to $3 \mathrm{~mm}$. A composite $3 \mathrm{~mm}$ thick board is suitable for hydrodynamic loading. It is necessary to have a fibres volume at least $35 \%$. This gives us the construction material with high toughness at impact load. With increasing volumetric filling decreasing the tension in board, thus also decreasing load on the expansion mechanism.
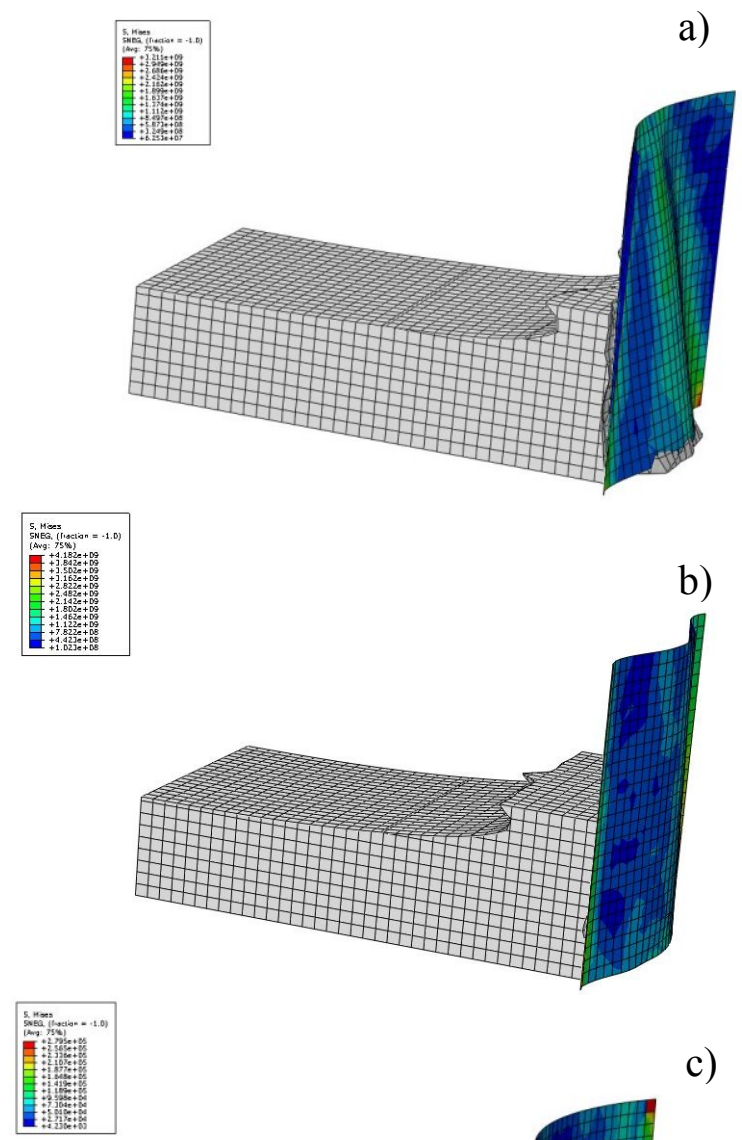

b)

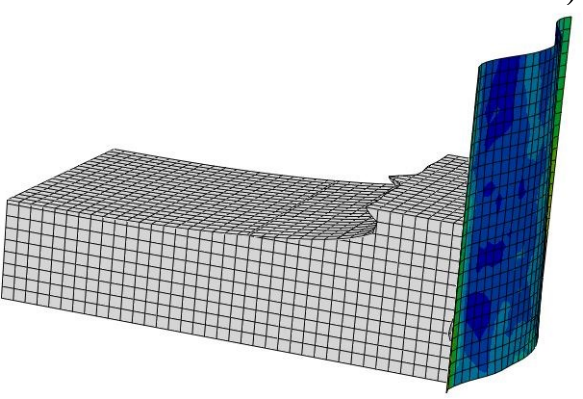

c)

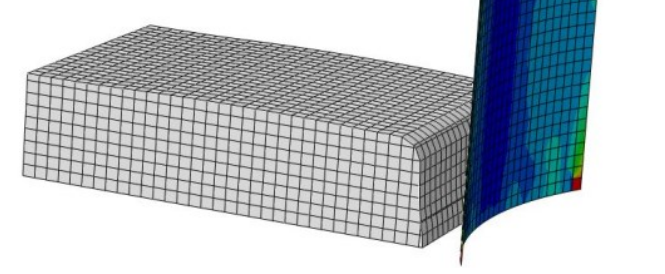

Fig. 3. FEM model of anti-flood board: a) thick $1,5 \mathrm{~mm}, \mathrm{~b}$ ) thick $2 \mathrm{~mm}, \mathrm{c}$ ) thick $3 \mathrm{~mm}$. 
Figure 4 shows results of the experiments. The horizontal axis of the plot shows the change in the building bore (longitudinal deformation of board). The vertical axis shows the force of board buckling for the given deformation and the force from the water pressure.

a)

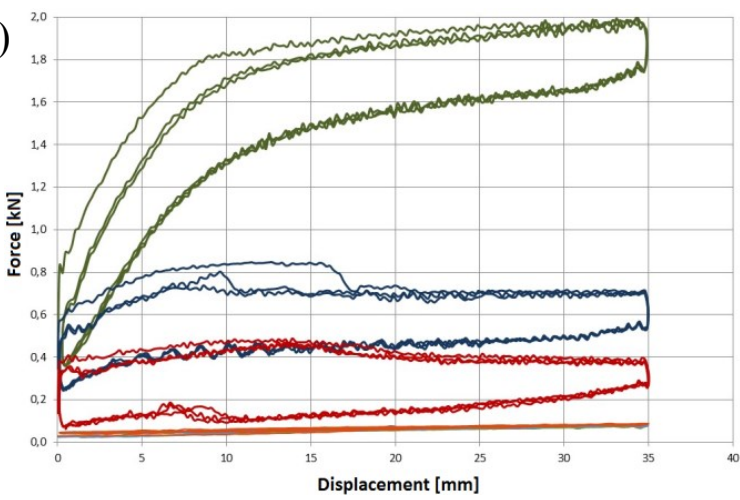

b)

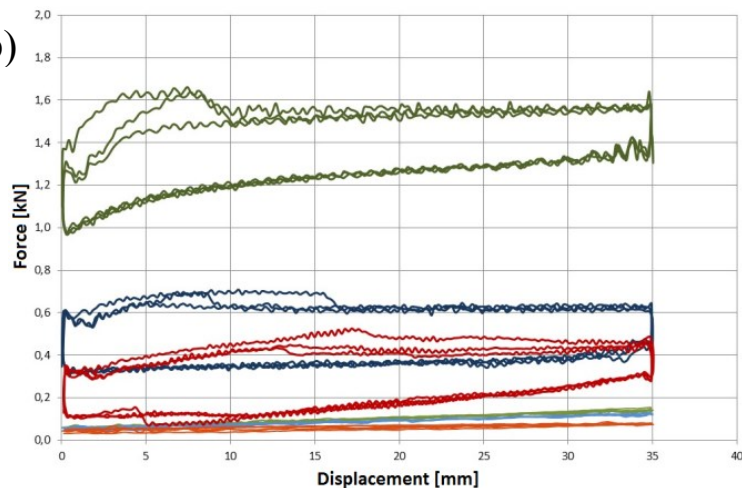

c)

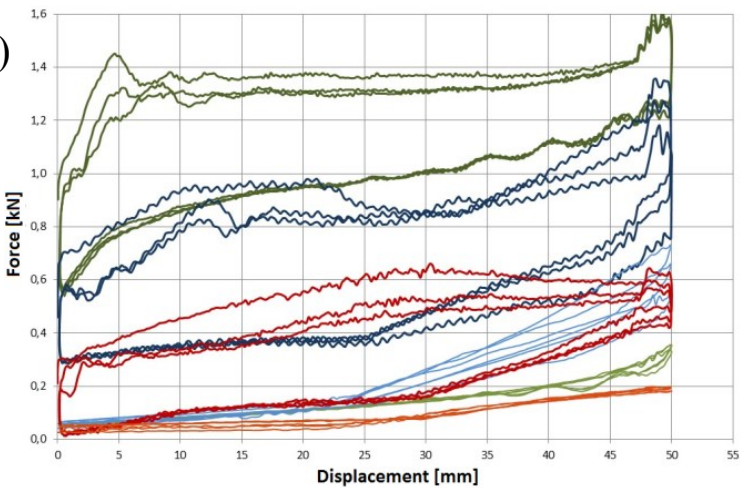

Fig. 4. Experimental measurement of the forces of loaded prototype: bore width a) $550 \mathrm{~mm}$, b) $650 \mathrm{~mm}$, c) $750 \mathrm{~mm}$.

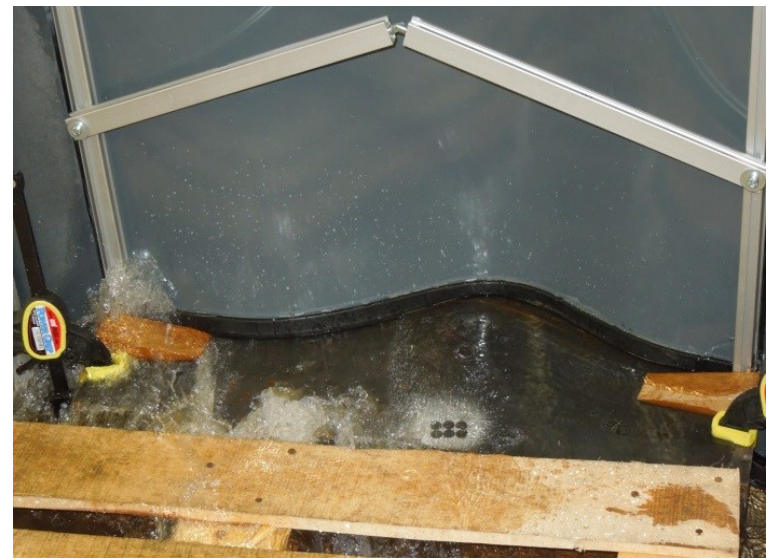

Fig. 5. Experimental measurement: hydrodynamic load of antiflood board

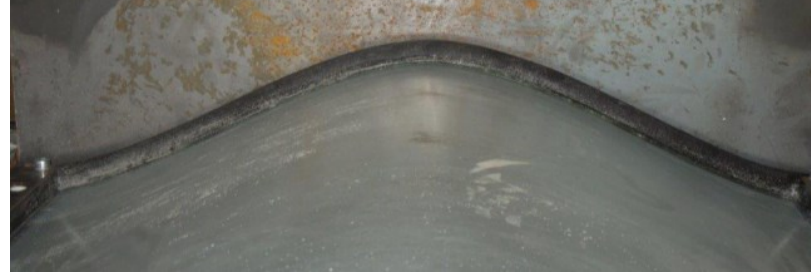

Fig. 6. Experimental measurement: detail of sealing.

Composites boards of 3 different thicknesses were measured (in plots $3 \mathrm{~mm}$ - green, $2 \mathrm{~mm}$ - blue, $1.5 \mathrm{~mm}$ red). The dark tint of colour displays the values of the vertical force, the light tint of the colour shows value of the side force. The board was place to testing frame first preload of height $15 \mathrm{~mm}$ was applied then were performed 3 cycles of height $35 \mathrm{~mm}$ loading. Measurements were carried out for three bores width 500 $\mathrm{mm}, 650 \mathrm{~mm}$ and $750 \mathrm{~mm}$. The tests show that the design is satisfactory with minimal fictional coefficient 0.15 . Due to the fact that the rubber seal (fig. 5, 6) increases this coefficient, the solution is applicable.

\section{Conclusions}

In case of a flood it is necessary to divert water out of the inhabited area as soon as possible. Fixed or mobile barriers are usually used in high urban density areas. To protect personal property in a low urban density areas are these barriers to expensive. Here are the best solution secure individual buildings against water ingress. This can be achieved by the using anti-flood board installed in building bores such as doors and windows. Board must meet many requirements, especially low weight and easy installation. Based on many mechanical tests and numerical simulations have been developed anti-flood board made of composite material. This new design meets all requirements and is characterized by its low weight and excellent sealing capability.

\section{Acknowledgements}

The results of this project VI20152018005 were obtained with co-funding from the Ministry of the Interior of the Czech Republic as part of targeted support from the project "Vývoj protipovodňových systémů pro zvýšení ochrany obyvatelstva a infrastruktury".

\section{References}

1. Approval Standard for Flood Abatement Equipment, Class Number 2510, FM Approvals LLC. (2013)

2. Muttray, M.O., Oumeraci, H. Theoretical and experimental study on wave damping inside a rubble mound breakwater (2005)

3. P. Srb, M. Petru and P. Kulhavy, Numerical simulation of flood barriers, EPJ Web of Conf. 143, 02115 (2017)

4. Syrovátková, M., Kulhavý, P., Srb, P., Petrů, M., Testing of tensile properties of carbon prepreg composite rods with adding of a non-composite part, (2016), Defect and Diffusion Forum 